\title{
Impairment of Sympathetic Activation during Static Exercise in Patients with Muscle Phosphorylase Deficiency (McArdle's Disease)
}

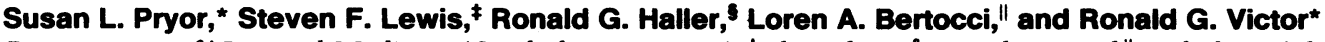 \\ Departments of ${ }^{*}$ Internal Medicine (Cardiology Division), ${ }^{\ddagger}$ Physiology, ${ }^{8}$ Neurology, and "Radiology, ${ }^{*}$ the Harry S. Moss Heart Center, \\ and "the Biomedical Nuclear Magnetic Resonance Center, University of Texas Southwestern Medical Center,
} Dallas, Texas 75235; and ${ }^{\S}$ the Veterans Administration Medical Center, Dallas, Texas 75216

\begin{abstract}
Static exercise in normal humans causes reflex increases in muscle sympathetic nerve activity (MSNA) that are closely coupled to the contraction-induced decrease in muscle cell pH, an index of glycogen degradation and glycolytic flux. To determine if sympathetic activation is attenuated when muscle glycogenolysis is blocked due to myophosphorylase deficiency (McArdle's disease), an inborn enzymatic defect localized to skeletal muscle, we now have performed microelectrode recordings of MSNA in four patients with McArdle's disease during static handgrip contraction. A level of static handgrip that more than doubled MSNA in normal humans had no effect on MSNA and caused an attenuated rise in blood pressure in the patients with myophosphorylase deficiency. In contrast, two nonexercise sympathetic stimuli, Valsalva's maneuver and cold pressor stimulation, evoked comparably large increases in MSNA in patients and normals. The principal new conclusion is that defective glycogen degradation in human skeletal muscle is associated with a specific reflex impairment in sympathetic activation during static exercise. (J. Clin. Invest. 1990. 85:1444-1449.) sympathetic nerve activity • microneurography - myophosphorylase deficiency ${ }^{31} \mathbf{P}$ nuclear magnetic resonance spectroscopy
\end{abstract}

\section{Introduction}

Static exercise causes increases in heart rate and blood pressure that are mediated by decreases in parasympathetic and increases in sympathetic neural activity $(1,2)$. These autonomic responses have been attributed both to neural signals arising in the central nervous system in association with voluntary motor effort, "central command" (3-6), and to reflexes caused by mechanically and chemically sensitive afferents in the contracting skeletal muscle (7-9). The relative contribution of these different mechanisms in the regulation of autonomic outflow during exercise may vary considerably depending on the experimental model and specific autonomic outflow under study $(6,10,11)$.

A preliminary report of this work was presented at the Annual Scientific Sessions of the American Heart Association (1987. Circulation. 76:IV-60.).

Address correspondence to Dr. Ronald G. Victor, Cardiology Division, U. T. Southwestern Medical Center, 5323 Harry Hines Blvd., Dallas, TX 75235-9034.

Received for publication 11 July 1989 and in revised form 1 No vember 1989.

J. Clin. Invest.

(c) The American Society for Clinical Investigation, Inc.

$0021-9738 / 90 / 05 / 1444 / 06 \$ 2.00$

Volume 85, May 1990, 1444-1449
Recent neurophysiologic studies in humans, for example, have provided substantial evidence that during moderate levels of static handgrip, stimulation of chemically sensitive muscle afferents is the principal mechanism responsible for increasing sympathetic outflow to resting skeletal muscle (10, 12). In contrast, central command and mechanically sensitive muscle afferents have no detectable effects on this particular sympathetic response $(10,13)$. The study of muscle sympathetic responses to static handgrip, therefore, provides an experimental approach to examine the function of chemically sensitive muscle afferents in conscious, exercising humans.

We recently have combined this approach with phosphorus nuclear magnetic resonance spectroscopy $\left({ }^{31} \mathrm{P} \text { NMR }\right)^{1}$ in an attempt to probe the specific metabolic events in contracting skeletal muscle that initiate the reflex stimulation of sympathetic outflow evoked by static exercise. We found that during static handgrip in normal humans, the onset of sympathetic activation in resting leg muscle coincided with the contraction-induced fall in forearm muscle cell $\mathrm{pH}$, an index of increased glycolytic flux resulting from glycogen degradation (12).

The goal of the present study, therefore, was to test the hypothesis that glycogen degradation in exercising skeletal muscle plays an important role in initiating the reflex stimulation of sympathetic outflow evoked by static contraction. To test this hypothesis we performed microelectrode recordings of muscle sympathetic nerve activity (MSNA) during static exercise in patients with myophosphorylase deficiency (McArdle's disease), a condition in which contraction is not accompanied by glycogen degradation in exercising skeletal muscle (14-16).

\section{Methods}

Four patients with myophosphorylase deficiency, ages 21-38 yr, participated in these studies. In each of the patients the diagnosis was established on the basis of a typical clinical history of exercise intolerance and exertional myoglobinuria, and muscle biopsy that showed absence of phosphorylase by histochemical and biochemical analysis. All four patients had completely normal neurological examination, 12-lead electrocardiograms, serum electrolytes, and hematocrits. One patient was taking L-thyroxine after complete thyroidectomy for a thyroid tumor in 1971; another patient was taking nadolol, which was discontinued $72 \mathrm{~h}$ before the study. Nine healthy volunteers matched for age, sex, and maximal handgrip strength served as control subjects. The study protocol was approved by the Institutional Review Board of human investigation and each subject and patient gave informed written consent to participate.

Multiunit recordings of efferent sympathetic nerve activity were obtained with a unipolar tungsten microelectrode inserted into a mus-

1. Abbreviations used in this paper: MSNA, muscle sympathetic nerve activity; MVC, maximal voluntary contraction; NMR, nuclear magnetic resonance; $\mathrm{PCr}$, phosphocreatine; $\mathrm{Pi}$, inorganic phosphate. 
cle fascicle of the right peroneal nerve posterior to the fibular head by microneurography. The details of this technique have been previously described (17). Postganglionic action potentials were amplified $20,000-50,000$-fold, filtered using a band width of $700-2,000 \mathrm{~Hz}$, rectified, and integrated (time constant, $0.1 \mathrm{~s}$ ) to obtain a mean voltage display of MSNA. An acceptable recording site was identified by neurograms that demonstrated spontaneous pulse-synchronized bursts which increased during expiration and during phases 2 and 3 of a Valsalva maneuver, but not during arousal stimuli (loud noise, skin pinch) (17). Sympathetic bursts were identified by inspection of the filtered and mean voltage neurograms. Simultaneous measurements of MSNA, arterial pressure (oscillometric sphygmomanometer; Critikon, Inc., Tampa, FL), heart rate (electrocardiogram), and force of contraction (handgrip dynamometer; Stoelting Co., Chicago, IL) were performed during a 2-min control period, followed by $90 \mathrm{~s}$ of static handgrip at $30 \%$ of maximal voluntary contraction (MVC) and a 2-min recovery period. All measurements were obtained with the subjects and patients in the supine position.

In eight additional experiments, we monitored cellular high energy phosphates and $\mathrm{pH}$ in exercising forearm muscle with ${ }^{31} \mathrm{P}$ NMR spectroscopy. The handgrip protocol was repeated on a separate day in seven normal subjects and one patient with myophosphorylase deficiency with the exercising forearm placed in a $30-\mathrm{cm}$ horizontal bore, 1.9-tesla superconducting magnet (Oxford Instruments, Oxford, UK) interfaced to a NT-80 console (GE/NMR, Freemont, CA). A 2-cm surface coil tuned to the resonance frequency of $32.5 \mathrm{mHz}$ for ${ }^{31} \mathrm{P}$ was positioned over the flexor digitorium profundis muscle. Magnetic resonance spectra were acquired in 30 -s intervals, representing the time average of 20 acquisitions. The cellular concentrations of phosphocreatine ( $\mathrm{PCr}$ ) and inorganic phosphate $(\mathrm{Pi})$ were measured by calculating the area of their respective peaks. Intracellular $\mathrm{pH}$ was estimated from the chemical shift of Pi relative to $\mathrm{PCr}$ (18). Free intracellular ADP was calculated using the creatine kinase equilibrium reaction, assuming an equilibrium constant of $5.5 \mathrm{mmol} / \mathrm{kg}$ for ATP and 32 $\mathrm{mmol} / \mathrm{kg}$ for $\mathrm{PCr}+\mathrm{Cr}(19)$.

We also examined MSNA responses evoked by baroreceptor deactivation during the Valsalva maneuver and by stimulation of cutaneous afferents during the cold pressor test (hand in ice water for $2 \mathrm{~min}$ ). These two reflex interventions were used as internal controls, i.e., as nonexercise stimuli to sympathetic outflow $(17,20)$. The order of interventions was randomized with 10 -min rest periods between interventions.

Statistical analysis was performed using repeated measures analysis of variance with the Bonferroni adjustment for multiple comparisons. Differences were considered statistically significant for $P<0.05$. Data are expressed as mean $\pm \mathrm{SE}$.

\section{Results}

Resting NMR spectra, peroneal neurograms, blood pressures, and heart rates all were normal in patients with myophosphorylase deficiency (Tables I and II, Figs. 1 and 2). In both patients and normal control subjects, resting neurograms revealed pulse-synchronous bursts of muscle sympathetic activity. At rest, the sympathetic nerves fired more frequently in the patients vs. controls: $36 \pm 6$ vs. $23 \pm 4$ bursts/min $(P<0.05)$. However, in two of the nine control subjects the resting level of sympathetic discharge was $\geq 40$ bursts/min, a level that was equivalent to that in the two patients with the highest levels of resting sympathetic discharge. Maximal handgrip strength was $39 \pm 6 \mathrm{~kg}$ in the normal subjects and $36 \pm 10 \mathrm{~kg}$ in the patients.

In normal subjects, static handgrip at $30 \%$ MVC decreased $\mathrm{PCr}$ and increased Pi and ADP, decreased $\mathrm{pH}$, and increased MSNA by $134 \%$ (Tables I and II, Figs. 1 and 2). Increases in MSNA were temporally correlated with decreases in muscle cell $\mathrm{pH}$, beginning 30-60 s from the onset of tension development. In contrast, in one patient with myophosphorylase defi-
Table I. Effects of Static Handgrip on Muscle Cell pH and High Energy Phosphates

\begin{tabular}{|c|c|c|c|c|}
\hline & \multicolumn{2}{|c|}{ Normal subjects } & \multicolumn{2}{|c|}{$\begin{array}{l}\text { Patient with } \\
\text { myophosphorylase } \\
\text { deficiency }\end{array}$} \\
\hline & Control & Handgrip & Control & Handgrip \\
\hline$[\mathrm{H}+](n M)$ & $79.4 \pm 0.3$ & $126 \pm 1.2$ & 85.1 & 77.6 \\
\hline $\mathrm{pH}$ & $7.1 \pm 0.1$ & $6.9 \pm 0.1$ & 7.1 & 7.1 \\
\hline$[\mathrm{PCr}](\mathrm{mmol} / \mathrm{kg}$ wet $w t)$ & $22.9 \pm 0.3$ & $14.7 \pm 1.1$ & 23.8 & 8.3 \\
\hline$[\mathrm{Pi}](\mathrm{mmol} / \mathrm{kg}$ wet $w t)$ & $2.6 \pm 0.2$ & $10.9 \pm 1.2$ & 4.8 & 22.5 \\
\hline [ADP] $(\mu \mathrm{mol} / \mathrm{kg}$ wet $w t)$ & $11.4 \pm 1.1$ & $27.4 \pm 6.1$ & 8.2 & 86.9 \\
\hline
\end{tabular}

Data are mean \pm SE for seven normal subjects and one patient with myophosphorylase deficiency. Entries are the average of $2 \mathrm{~min}$ of control measurements and the last $30 \mathrm{~s}$ of a 90 -s static handgrip at $30 \%$ MVC

ciency in whom ${ }^{31} \mathrm{P}$ NMR spectroscopy was performed, handgrip had no effect on $\mathrm{pH}$ but caused excessive decreases in $\mathrm{PCr}$ and increases in Pi and ADP (Table I, Fig. 1). Most importantly, even though force production was comparable in the two groups, handgrip caused no increase in MSNA in any of the four patients with myophosphorylase deficiency, even though this maneuver more than doubled MSNA in the normal subjects (Table II, Figs. 2 and 3). The exercise-induced rise in blood pressure also was greatly attenuated in the patients, but exercise-induced increases in heart rate were comparable

NORMAL SUBJECT

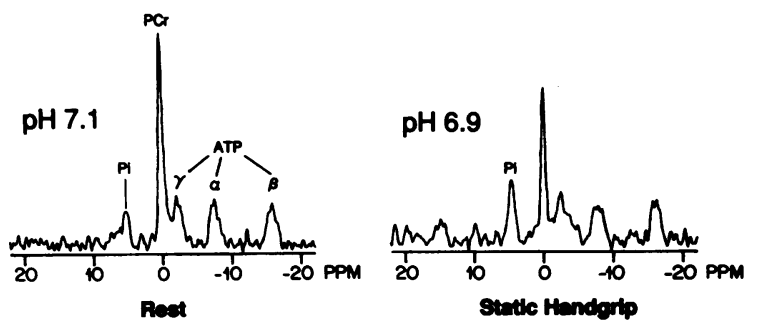

PATIENT WITH MYOPHOSPHORYLASE DEFICIENCY

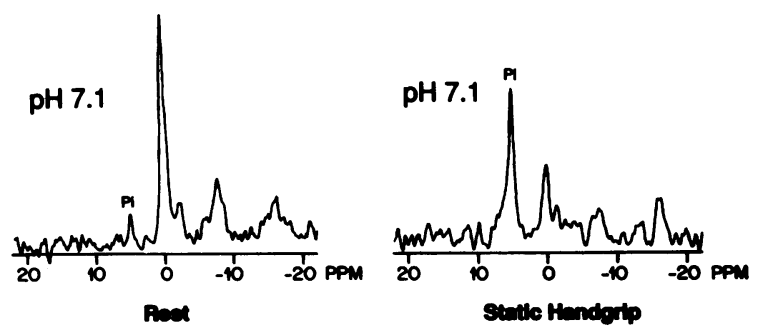

Figure 1. Illustrative 31P NMR spectra at rest and during static handgrip at $30 \%$ of maximal voluntary contraction (MVC) in two subjects. Data represent the last $30 \mathrm{~s}$ of each measurement period. In each spectra, the signal intensities are proportional to the cellular concentrations of $\mathrm{Pi}, \mathrm{PCr}$, and the three phosphates of ATP. In the normal subject, handgrip increased $\mathrm{Pi}$ as $\mathrm{PCr}$ decreased, and decreased $\mathrm{pH}$ (estimated from rightward shift of $\mathrm{Pi}$ relative to $\mathrm{PCr}$ ). In the patient with myophosphorylase deficiency, despite an excessive increase in $\mathrm{Pi}$ and decrease in $\mathrm{PCr}$, handgrip caused no decrease in $\mathrm{pH}$. 


\begin{tabular}{|c|c|c|c|c|c|}
\hline & \multirow[b]{2}{*}{ Control } & \multicolumn{3}{|c|}{ Static handgrip } & \multirow[b]{2}{*}{ Recovery } \\
\hline & & $0-30 \mathrm{~s}$ & $30-60 \mathrm{~s}$ & $60-90 \mathrm{~s}$ & \\
\hline \multicolumn{6}{|l|}{ Normal subjects* } \\
\hline MSNA (total activity) ${ }^{\ddagger}$ & $304 \pm 48$ & $287 \pm 38$ & $502 \pm 76^{8}$ & $700 \pm 105^{\S}$ & $400 \pm 52$ \\
\hline MSNA (bursts/min) & $23 \pm 4$ & $22 \pm 4$ & $34 \pm 6^{8}$ & $41 \pm 5^{\S}$ & $28 \pm 5$ \\
\hline $\mathrm{MAP}(\mathrm{mmHg})$ & $89 \pm 2$ & $95 \pm 3^{8}$ & $101 \pm 3^{8}$ & $110 \pm 3^{\S}$ & $89 \pm 3$ \\
\hline HR (beats/min) & $65 \pm 3$ & $71 \pm 3^{8}$ & $76 \pm 3^{8}$ & $80 \pm 3^{8}$ & $66 \pm 3$ \\
\hline Force $(k g)$ & & $12 \pm 2$ & $12 \pm 2$ & $12 \pm 2$ & \\
\hline \multicolumn{6}{|c|}{ Patients with myophosphorylase deficiency" } \\
\hline \multicolumn{6}{|c|}{ Patient 1} \\
\hline MSNA (total activity) ${ }^{\ddagger}$ & 531 & 488 & 380 & 435 & 459 \\
\hline MSNA (bursts/min) & 38 & 38 & 30 & 38 & 40 \\
\hline $\mathrm{MAP}(\mathrm{mmHg})$ & 85 & 88 & 91 & 91 & 87 \\
\hline HR (beats/min) & 71 & 78 & 80 & 90 & 74 \\
\hline Force $(k g)$ & & 5 & 5 & 5 & \\
\hline \multicolumn{6}{|l|}{ Patient 2} \\
\hline MSNA (total activity) $)^{\ddagger}$ & 560 & 475 & 534 & 464 & 500 \\
\hline MSNA (bursts/min) & 44 & 34 & 40 & 36 & 41 \\
\hline $\operatorname{MAP}(m m H g)$ & 97 & 98 & 99 & 99 & 97 \\
\hline HR (beats/min) & 81 & 82 & 85 & 88 & 82 \\
\hline Force $(k g)$ & & 7 & 7 & 7 & \\
\hline \multicolumn{6}{|l|}{ Patient 3} \\
\hline MSNA (total activity) ${ }^{\ddagger}$ & 682 & 686 & 649 & 739 & 739 \\
\hline MSNA (bursts/min) & 44 & 46 & 41 & 45 & 45 \\
\hline $\operatorname{MAP}(m m H g)$ & 88 & 91 & 95 & 96 & 88 \\
\hline HR (beats/min) & 68 & 71 & 75 & 78 & 67 \\
\hline Force $(k g)$ & & 17 & 17 & 17 & \\
\hline \multicolumn{6}{|l|}{ Patient 4} \\
\hline MSNA (total activity) $)^{\ddagger}$ & 166 & 85 & 112 & 217 & 181 \\
\hline MSNA (bursts/min) & 18 & 10 & 13 & 22 & 19 \\
\hline $\operatorname{MAP}(\mathrm{mmHg})$ & 85 & 85 & 87 & 92 & 84 \\
\hline HR (beats/min) & 55 & 61 & 67 & 70 & 57 \\
\hline Force $(k g)$ & & 17 & 17 & 17 & \\
\hline \multicolumn{6}{|l|}{ Mean \pm SE } \\
\hline MSNA (total activity) ${ }^{\ddagger}$ & $485 \pm 111$ & $434 \pm 126$ & $419 \pm 116$ & $464 \pm 107$ & $470 \pm 114$ \\
\hline MSNA (bursts/min) & $36 \pm 6$ & $32 \pm 8$ & $31 \pm 6$ & $35 \pm 5$ & $36 \pm 6$ \\
\hline $\operatorname{MAP}(m m H g)$ & $89 \pm 3$ & $91 \pm 3$ & $93 \pm 3^{8}$ & $95 \pm 2^{8}$ & $89 \pm 3$ \\
\hline HR (beats/min) & $69 \pm 5$ & $73 \pm 5$ & $77 \pm 4^{8}$ & $82 \pm 5^{8}$ & $70 \pm 5$ \\
\hline Force $(k g)$ & & $12 \pm 3$ & $12 \pm 3$ & $12 \pm 3$ & \\
\hline
\end{tabular}

${ }^{*}$ Entries are mean $\pm \mathrm{SE}$ for nine subjects. ${ }^{\ddagger} \mathrm{MSNA}$ is expressed as total activity (bursts/minute $\times$ mean burst amplitude). ${ }^{\S} P<0.05$ vs. control values. "Entries are data for MSNA, MAP, HR and force during static handgrip at 30\% MVC in four patients with myophosphorylase deficiency.

in the two groups (Table II, Fig. 3). At the end of handgrip exercise, three of the four patients developed forearm contractures lasting 10-20 min. This contracture caused pain, but no increase in MSNA, blood pressure, or heart rate.

Unlike handgrip, which had no effect on MSNA in patients with myophosphorylase deficiency, two nonexercise stimuli to sympathetic outflow, the Valsalva maneuver and the cold pressor test, evoked comparably large increases in MSNA in patients and normal subjects (Table III, Figs. 4 and 5).

\section{Discussion}

We performed direct measurements of sympathetic nerve discharge in humans with a specific inborn error of skeletal mus- cle metabolism to examine the relationship between muscle metabolism and sympathetic outflow during static exercise. The major new finding is that a level of static handgrip that consistently elicits large increases in muscle sympathetic outflow in normal humans has no effect on this sympathetic outflow in patients with myophosphorylase deficiency. This observation strongly suggests that without glycogen degradation in contracting muscle static exercise alone is not sufficient to stimulate muscle sympathetic outflow in humans.

This interpretation is predicated on the assumption that the enzymatic defect in these patients is limited to skeletal muscle and does not involve afferent, central, and efferent neural pathways. There is substantial evidence to suggest that skeletal muscle phosphorylase deficiency is not associated with 
PATIENT WITH MYOPHOSPHORYLASE DEFICIENCY

MSNA

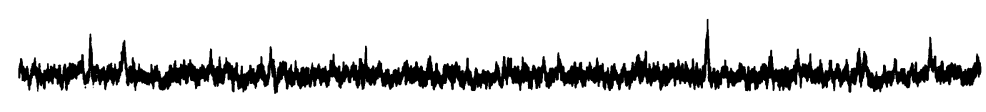

Figure 2. Segments of original records from one normal subject and one patient with myophosphorylase deficiency showing recordings of MSNA during $90 \mathrm{~s}$ of static handgrip at $30 \%$ of MVC. Static handgrip markedly increased the frequency and amplitude of the sympathetic neural bursts in the normal subject but had no effect on MSNA in the patient with myophosphorylase deficiency despite comparable force production. abnormal phosphorylase activity in either cardiac or vascular smooth muscle (21). In our patients, preservation of reflex sympathetic activation during Valsalva's maneuver and during cold pressor stimulation strongly suggests that efferent sympathetic pathways were intact and could respond appropriately to deactivation of baroreceptors and to activation of somatic afferents in skin. The additional finding that our patients experienced muscular pain during handgrip-induced contracture of the forearm flexor muscles indicates that somatic afferents, presumably unmyelinated afferents, were also intact in skeletal muscle. Unmyelinated fibers are the subtype of afferents that, in anesthetized animal preparations, are stimulated not only by algesic substances, but also by chemical products of muscle contraction (7).

Because the resting frequency of sympathetic discharge was on the average higher in the patients than in our control subjects, we considered the possibility that in the patients with the highest levels of resting sympathetic discharge, MSNA already was maximal at rest and thus could not possibly have increased further with static handgrip. This possibility is unlikely for two reasons. First, two of our nine normal control subjects had resting levels of nerve traffic that were $\geq \mathbf{4 0}$ bursts $/ \mathrm{min}$, levels that were just as high as those seen in the two patients
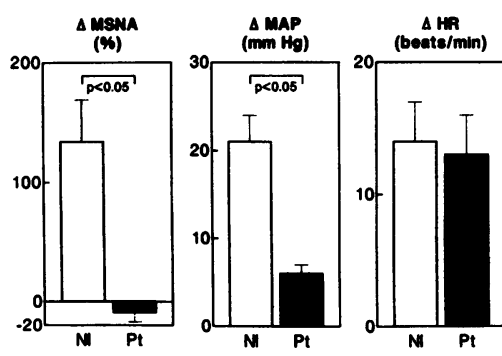

Figure 3. Peak increases in total MSNA, mean arterial pressure $(M A P)$, and heart rate $(H R)$, evoked by static handgrip in normal subjects (open bars) and patients with myophosphorylase deficiency (solid bars).

Entries are mean $\pm \mathrm{SE}$ for nine normal subjects and four patients. Compared with normals, static handgrip caused no increase in MSNA and a greatly attenuated pressor response in the patients. In contrast, handgrip-induced increases in heart rate were comparable in the two groups. with the highest number of bursts/minute at rest. Nevertheless, these two control subjects showed large increases in MSNA with static handgrip, increases that were just as large as those seen in our other seven control subjects. Second, the Valsalva maneuver, a standard baroreflex stimulus to MSNA, evoked equally large increases in sympathetic activity in our patients and control subjects.

We therefore suggest that the abnormal metabolism in contracting skeletal muscle explains the failure of static handgrip to increase MSNA in patients with myophosphorylase deficiency. Our findings suggest several possible mechanisms whereby glycogen degradation may be an important step in the activation of the muscle afferents that reflexly increase MSNA during handgrip in normal humans. One possibility is that these afferents are activated directly by hydrogen ions resulting from glycolytic production of lactic acid. From these human experiments, however, we cannot exclude the alternative possibility that such afferents might be activated either by products of glycogen breakdown and glycolysis other than hydrogen ions, or by nonglycolytic products whose accumulation in

Table III. Peak Muscle Sympathetic Nerve Responses during Valsalva Maneuver

\begin{tabular}{ccc}
\hline & Control & $\begin{array}{c}\text { Valsalva maneuver } \\
\text { (phases 2 and 3) }\end{array}$ \\
\hline Normals & & \\
Bursts/minute & $26 \pm 1$ & $56 \pm 4^{*}$ \\
$\quad$ Total activity & $333 \pm 32$ & $1,265 \pm 125^{*}$ \\
$\begin{array}{c}\text { Patients } \\
\text { Bursts/minute }\end{array}$ & $35 \pm 4$ & $63 \pm 3^{*}$ \\
Total activity & $453 \pm 107$ & $1,063 \pm 137^{*}$ \\
\hline
\end{tabular}

Entries are mean \pm SE for nine normal subjects and four patients with myophosphorylase deficiency. Values represent MSNA expressed as burst frequency (bursts/minute) and as total activity per minute (bursts/minute $\times$ mean burst amplitude). ${ }^{*} P<0.05$ vs. control values. 


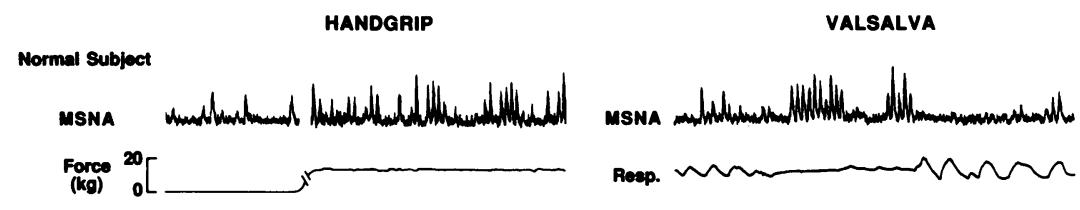

Figure 4. Original records of MSNA in two subjects showing peak responses during static handgrip at 30\% MVC and during phases 2 and 3 of a Valsalva maneuver. Whereas MSNA responses evoked by static handgrip were markedly attenPationt With
Myophosephoryleas
Deficlency

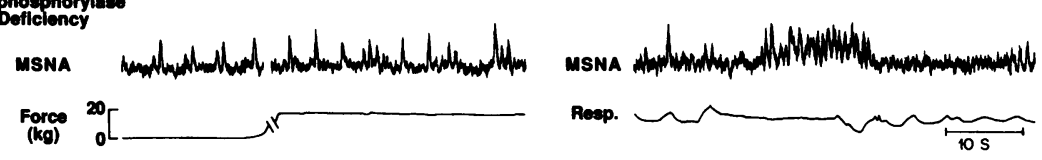
uated in the patient with myophosphorylase deficiency, increases in MSNA evoked by the Valsalva maneuver were comparable in the normal subject and patient.

the muscle interstitium is facilitated by intramuscular acidification.

Our data also are consistent with several recent reports. In anesthetized animals, lactic acid has been shown to stimulate muscle afferents $(22,23)$ and reflexly increase arterial pressure (24). In conscious dogs, the pressor response to progressive muscle ischemia during treadmill exercise was strongly correlated to venous effluent pH (25). In normal humans, we previously found a close temporal relationship between decreases in forearm muscle cell $\mathrm{pH}$ and increases in peroneal MSNA during static handgrip (12), an observation that we now have replicated in the present experiments. Sinoway et al. (26) recently found a similar relationship in normal subjects between handgrip-induced decreases in forearm muscle cell $\mathrm{pH}$ and increases in calf vascular resistance, the latter being the functional consequence of increased MSNA.

Our findings in patients with myophosphorylase deficiency do not exclude the possibility that in normal humans metabolic processes other than glycogen degradation and glycolysis also might be important in the reflex regulation of autonomic outflow during exercise. Studies in anesthetized animals, for example, have advanced the concept that mitochondrial respiration in active muscle evokes reflex increases in cardiac output (27). Previous studies in humans have suggested that a reduced availability of substrate for mitochondrial respiration in myophosphorylase deficient muscle explains the observation that, for a given increase in total body oxygen consumption during dynamic leg exercise, these patients show exagger-

NORMAL SUBJECT

MSNA

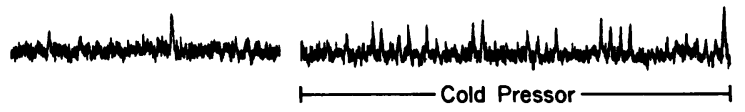

PATIENT WITH MYOPHOSPHORYLASE DEFICIENCY

MSNA

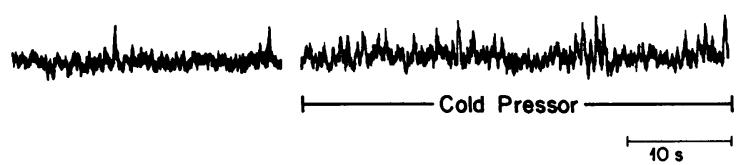

Figure 5. Recordings of MSNA showing responses to the cold pressor test in two subjects. Cold pressor stimulation evoked comparably large increases in MSNA in the normal subject and in the patient with myophosphorylase deficiency. ated increases in cardiac output and resultant increases in blood pressure (28).

During static handgrip, however, the principal metabolites that normally stimulate mitochondrial respiration, ADP, and $\mathrm{Pi}$ are unlikely to be important determinants of sympathetic outflow to resting skeletal muscle. Our patients with myophosphorylase deficiency showed no increase in MSNA during handgrip despite augmented cellular accumulation of these phosphorus-containing metabolites $(28-30)$. These data are consistent with our previous findings that during handgrip in normal humans increases in MSNA are temporally dissociated from the cellular accumulation of ADP and Pi (12).

Because we recorded sympathetic outflow targeted specifcally to skeletal muscle, our conclusions cannot be directly extrapolated to other tissues and regional vascular beds involved in the cardiovascular adjustments to static exercise. Blood pressure and heart rate responses in patients with myophosphorylase deficiency, however, may provide some important clues about the neural regulation of these hemodynamic variables during static exercise in normal humans. Attenuation of the handgrip-induced rise in blood pressure in our patients with impaired activation of MSNA supports the view that the characteristically large increases in blood pressure seen during static handgrip in normal humans are caused in part by reflex activation of MSNA (31).

Unlike blood pressure and MSNA, heart rate increased normally during handgrip in our patients. This finding is consistent with the evolving concept that central command, rather than muscle afferents, is the principal mechanism that increases heart rate during this form of exercise $(10,13)$.

In summary, this study documents a specific impairment in reflex sympathetic discharge during static handgrip in humans with myophosphorylase deficiency. In normal humans, glycogen degradation in exercising skeletal muscle may be a necessary condition for the activation of this contraction-induced sympathetic reflex.

\section{Acknowledgments}

The authors gratefully acknowledge the continued support and thoughtful advice of Dr. Jere H. Mitchell. We also thank Janet Batjer and Pamela Maass for assistance in preparation of the manuscript and Lilia Urias for technical assistance.

This work was supported by NHLBI Program Project Grant HL-06296 (S. F. Lewis and R. G. Victor), Training Grant HL-07360 (S. L. Pryor and L. A. Bertocci), Research Career Development Award HL-01581 (S. F. Lewis), Clinical Investigator Award HL-01886 (R. G. Victor), and grants from the Muscular Dystrophy Association (R. G. 
Haller), the Veterans Administration (R. G. Haller), the American Heart Association-Texas Affiliate (S. L. Pryor and R. G. Victor), an Institutional Grant from University of Texas Southwestern Medical Center (S. L. Pryor), and the Lawson and Rogers Lacy Research Fund in Cardiovascular Diseases, University of Texas Southwestern Medical Center.

\section{References}

1. Lind, A. R., R. W. Humphreys, B. M. Kennelly, and K. W. Donald. 1964. The circulatory effects of sustained voluntary muscle contraction. Clin. Sci. 27:229-244.

2. Martin, C. E., J. A. Shaver, D. F. Leon, M. E. Thompson, P. S. Reddy, and J. J. Leonard. 1974. Autonomic mechanisms in hemodynamic responses to isometric exercise. J. Clin. Invest. 54:104-115.

3. Krogh, A., and J. Lindhard. 1913. The regulation of respiration and circulation during the initial stages of muscular work. J. Physiol. (Lond.). 47:112-136.

4. Goodwin, G. M., D. I. McCloskey, and J. H. Mitchell. 1972. Cardiovascular and respiratory responses to changes in central command during isometric exercise at constant muscle tension. J. Physiol. (Lond.). 226:173-190.

5. Eldridge, F. L., D. E. Millhorn, J. P. Kiley, and T. G. Waldrop. 1985. Stimulation by central command of locomotion, respiration, and circulation during exercise. Respir. Physiol. 59:313-337.

6. Leonard, B., J. H. Mitchell, M. Mizuno, N. Rube, B. Saltin, and N. H. Secher. 1985. Partial neuromuscular blockade and cardiovascular responses to static exercise at constant muscle tension. J. Physiol. (Lond.). 359:365-379.

7. Kaufman, M. P., J. C. Longhurst, K. J. Rybicki, J. H. Wallach, and J. H. Mitchell. 1983. Effects of static muscular contraction on impulse activity of group III and IV afferents in cats. J. Appl. Physiol. 55:105-112.

8. Mense, S., and M. Stahnke. 1983. Responses in muscle afferent fibers of slow conduction velocity to contractions and ischemia in the cat. J. Physiol. (Lond.). 342:383-397.

9. Mitchell, J. H., and R. F. Schmidt. 1983. Cardiovascular reflex control by afferent fibers from skeletal muscle receptors. In Handbook of Physiology, Vol. III, Part 2. J. T. Shepherd, and F. M. Abboud, editors. American Physiological Society (APS), Bethesda, MD. 623-658.

10. Mark, A. L., R. G. Victor, C. Nerhed, and B. G. Wallin. 1985. Microneurographic studies of the mechanisms of sympathetic nerve responses to static exercise in humans. Circ. Res. 57:461-469.

11. Victor, R. G., D. M. Rotto, S. L. Pryor, and M. P. Kaufman. 1989. Stimulation of renal sympathetic activity by static contraction: evidence for mechanoreceptor-induced reflexes from skeletal muscle. Circ. Res. 64:592-599.

12. Victor, R. G., L. A. Bertocci, S. L. Pryor, and R. L. Nunnally. 1988. Sympathetic nerve discharge is coupled to muscle cell pH during exercise in humans. J. Clin. Invest. 82:1301-1305.

13. Victor, R. G., S. L. Pryor, N. H. Secher, and J. H. Mitchell. 1989. Effects of partial neuromuscular blockade on sympathetic nerve responses to static exercise in humans. Circ. Res. 65:468-476.

14. McArdle, B. 1951. Myopathy due to a defect in muscle glycogen breakdown. Clin. Sci. 10:13-32.
15. Schmidt, R., and R. Mahler. 1959. Chronic progressive myopathy with myoglobinuna. Demonstration of a glycogenolytic defect in the muscle. J. Clin. Invest. 38:2044-2058.

16. Pearson, C. M., D. G. Riner, and W. F. H. M. Mommaerts. 1961. A metabolic myopathy due to absence of muscle phosphorylase. Am. J. Med. 30:502-517.

17. Vallbo A. B., K.-E. Hagbarth, H. E. Torebjork, and B. G. Wallin. 1979. Somatosensory proprioceptive, and sympathetic nerve activity in human nerves. Physiol. Rev. 59:919-957.

18. Moon, R. B., and J. H. Richards. 1973. Determination of intracellular $\mathrm{pH}$ by $31 \mathrm{P}$ nuclear magnetic resonance. J. Biol. Chem. 284:7276-7278.

19. Taylor, D. J., P. Styles, P. M. Matthews, D. A. Arnold, D. G. Dadian, P. Bore, and G. K. Radda. 1986. Energetics of human muscle exercise-induced ATP depletion. Magn. Reson. Med. 3:44-54.

20. Victor, R. G., W. N. Leimbach, D. R. Seals, B. G. Wallin, and A. L. Mark. 1987. Effects of the cold pressor test on muscle sympathetic nerve activity in humans. Hypertension (Dallas). 9:429-436.

21. DiMauro, S., and N. Bresolin. 1986. Phosphorylase deficiency. In Myology: Basic and Clinical. A. G. Engel and B. Q. Banker, editors. McGraw-Hill Book Company, New York. 1585-1601.

22. Thimm, F., and K. Baum. 1987. Response of chemosensitive nerve fibers of group III and IV to metabolic changes in rat muscles. Pfluegers Arch. Eur. J. Physiol. 410:143-152.

23. Rotto, D. M., and M. P. Kaufman. 1988. Effect of metabolic products of muscular contraction on discharge of group III and IV afferents. J. Appl. Physiol. 64:2306-2313.

24. Rotto, D. M., C. L. Stebbins, and M. P. Kaufman. 1989. Reflex cardiovascular and ventilatory responses to increasing hydrogen ion activity in hindlimb skeletal muscle of cats. J. Appl. Physiol. 67:256263.

25. Sheriff, D. D., C. R. Wyss, L. B. Rowell, and A. M. Scher. 1987. Does inadequate oxygen delivery trigger pressor response to muscle hypoperfusion during exercise? Am. J. Physiol. 253 (Heart Circ. Physiol. 22): H1199-H1207.

26. Sinoway, L., S. Phophet, I. Gorman, T. Mosher, J. Shenberger, M. Dolecki, R. Briggs, and R. Zelis. 1989. Muscle acidosis during static exercise is associated with calf vasoconstriction. J. Appl. Physiol. 66:429-436.

27. Liang, C.-S., and W. B. Hood, Jr. 1973. Comparison of cardiac output responses to 2,4-dinitrophenol-induced hypermetabolism and muscular work. J. Clin. Invest. 52:2283-2292.

28. Lewis, S. F., and R. G. Haller. 1986. The pathophysiology of McArdle's disease: clues to regulation in exercise and fatigue. J. Appl. Physiol. 65:391-401.

29. Ross, B. D., G. K. Radda, D. G. Gaddian, G. Rocker, M. Esiri, and J. Falconer-Smith. 1981. Examination of a case of suspected McArdle's syndrome by ${ }^{31} \mathrm{P}$ nuclear magnetic resonance. $N$. Engl. $J$. Med. 304:1338-1342.

30. Lewis, S. F., R. G. Haller, J. D. Cook, and R. L. Nunnally. 1985. Muscle fatigue in McArdle's disease studied by 31 P NMR: effect of glucose infusion. J. Appl. Physiol. 59:1991-1994.

31. Seals, D. R., P. B. Chase, and J. A. Taylor. 1988. Autonomic mediation of the pressor responses to isometric exercise in humans. $J$. Appl. Physiol. 64:2190-2196. 